\title{
ПРАВА ИНФОРМАТОРОВ В ЦЕНТРЕ ОБЩЕСТВЕННО-ПОЛИТИЧЕСКОЙ ЖИЗНИ ЕВРОСОЮЗА
}

\begin{abstract}
Аннотация. В статье проанализировано взаимодействие Комиссии ЕС, Совета ЕС и Европарламента по директиве о защите прав информаторов. Автор показывает, как в результате длительной и упорной борьбы Европарламенту удалось склонить к компромиссу Совет EC, члены которого заняли изначально противоположные позиции по проблеме последовательности передачи сигнала информаторами. Автор наглядно показывает сложность законодательного процесса в Европейском союзе, который может тянуться годами, пока законодатели не придут к согласию. Показаны позиции некоторых государств-членов по проблеме иерархии информирования и представлены их мотивации. Автор приходит к выводу, что институтам Европейского союза удалось достигнуть согласия по директиве благодаря скорым выборам в Европарламент, накануне которых важно было продемонстрировать конкретные результаты законотворческой деятельности.
\end{abstract}

Ключевые слова: информаторы, защита прав, директива, меж-институциональные переговоры, профсоюзы, Европейский парламент, Комиссия ЕС, Совет ЕС, блокирующее меньиинство.

Скандалы последних лет c Luxleaks (схема уклонения от корпоративных налогов в Люксембурге), с концерном Фольксваген (Дизельгейт), Панамским досье, а также компанией Сатbridge Analytica привлекли внимание общественности и правозащитных организаций европейских стран, поскольку главную роль в разоблачении злоупотреблений в каждом из этих случаев сыграли информаторы, рискуя при этом своим положением. Проблема защиты прав информаторов оказалась в центре общественно-политической повестки дня Европейского союза.

23 апреля 2018 г. Комиссия ЕС выступила с законодательной инициативой о директиве, цель которой - предоставить как государственным, так и частным компаниям правовую базу для определения прав и обязанностей информаторов. Инициатива Комиссии ЕС обсуждалась в обстановке интенсивной критики правозащитников, обеспокоенных слабой защитой ответственных граждан, которые сигнализируют о нарушениях законодательства Евросоюза. По мнению Комиссии, директива могла бы защитить информаторов от несправедливого обращения - попыток мести, дискриминации и нанесения ущерба; придаст смелости людям сообщать о злоупотреблениях, которые можно выявить, остановить и наказать виновников. Комиссия назвала защиту информаторов важным средством соблюдения законов. До сих пор в лишь в 10 странах ЕС применялись законодательства различной степени эффективности: в Ирландии - хорошо разработанные законы, на Кипре же не было совсем никаких ${ }^{1}$. Правозащитная организация Transparency International уже давно призывала к разработке общеевропейских

(C) Потемкина Ольга Юрьевна - доктор политических наук, гравный научный сотрудник, руководитель Отдела исследований европейской интеграции ИЕ РАН. Адрес: 125009, Россия, Москва, ул. Моховая, д. 11, стр. 3.E-mail: olga_potemkina@mail.ru.

DOI: http://dx.doi.org/10.15211/vestnikieran220199298

${ }^{1}$ Worth M. Safe or Sorry: Whistleblower Protection Laws in Europe Deliver Mixed Results. Blueprint Report Series, 2018. 58 P. 
правил защиты прав информаторов и горячо приветствовала инициативу Комиссии, которой предшествовал двухлетний этап публичных консультаций и дискуссий ${ }^{1}$.

Комиссия высказала уверенность, что директива изменит правила игры в бизнесе и политике, так как от компаний потребуется не только установить внутренние каналы, по которым сотрудники организаций могут сообщать руководству о нарушениях, но и оказать защиту сознательным гражданам от увольнения, понижения в должности и даже судебного разбирательства. В проекте директивы Комиссия предложила трёхступенчатую процедуру информирования: сначала сообщение о нарушениях следует передавать по внутреннему каналу (в собственной организации), потом уже сигнализировать вовне (компетентным властям за пределами компании) и только после этого информацию можно выносить на широкую публику.

Компании со штатом более 50 сотрудников и годовым оборотом более 10 млн евро должны будут, в соответствии с директивой, разработать процедуру рассмотрения и обработки докладов информаторов. Те же положения распространяются на государственные, региональные администрации и муниципалитеты в пунктах с населением более 10 тыс. человек. Предложенные Комиссией новые правила призваны оказать защиту гражданам, которые разоблачают противозаконные действия в сфере госзакупок, финансовых услуг, отмывания денег, ядерной и продовольственной безопасности, защиты персональной информации и др. В директиве предполагается введение специального механизма противодействия злонамеренным и искажающим факты сигналам и, в то же время, сохранение анонимности информатора. Роль профсоюзов будет усилена, особенно в обеспечении эффективности внутренних каналов уведомления ${ }^{2}$.

Для того чтобы директива вступила в силу, она должна была получить одобрение Совета ЕС и Европейского парламента. 20 ноября 2018 г. правовой комитет Европарламента одобрил проект директивы и подготовил свою позицию для переговоров с Советом ЕС. Евродепутаты внесли поправки в вариант Комиссии: они предложили распространить защиту не только на самих информаторов, но и на тех, кто помогал им подготовить разоблачительную информацию. Трёхступенчатое информирование (внутренний канал организации, уведомление компетентных властей за её пределами, сообщение для СМИ) получило поддержку в принципе, но с существенной оговоркой: передача разоблачающей информации журналистам напрямую, возможна в случае очевидного конфликта интересов между организацией, уличённой в нарушениях и ведомством, которому направлена жалоба, а также при угрозе уничтожения доказательств. Таким образом, по мнению Европарламента, процесс информирования в определённых случаях можно сократить до двух стадий.

В свою очередь, 25 января 2019 г. Совет (на уровне послов) принял модифицированную версию директивы и также подготовил переговорную позицию. Группа влиятельных государств - членов, включая Францию и Германию, настаивали на обязанности информатора доложить о выявленных им нарушениях сначала внутри компании, только в этом случае он мог бы претендовать на защиту своих прав.

\section{Блокирующее менышинство и меж-институциональные разногласия}

Франция изначально поддерживала «принцип иерархии каналов сообщений о нарушениях», в соответствии со своим национальным законодательством. Позицию Франции разделяла и Германия, настаивая на трёхступенчатой процедуре информирования о нарушениях

\footnotetext{
${ }^{1}$ Потемкина О.Ю. Кампания по защите прав информаторов. Европейский союз: факты и комментарии, №90, 2017. C. 37-39.

${ }_{2}$ Proposal for a Directive of the European Parliament and of the Council on the protection of persons reporting on breaches of Union law.COM/2018/218 final - 2018/0106 (COD).
}

Научно-аналитический вестник ИЕ РАН, 2019, №2 
как «красной линии», за пределы которой не намерена отступать ${ }^{1}$. С 2008 г. в Германии было выдвинуто шесть законодательных инициатив о правах информаторов, и ни одна не прошла.

Председательствующая Румыния заявила о наличии блокирующего меньшинства в Совете, которое противится внесению изменений в первоначальный вариант директивы, предложенный Комиссией. Комиссия же пыталась найти компромисс между различными мнениями о процедуре информирования: она предложила ввести информирование по внутренним каналам компании как первый шаг, но в исключительных случаях, когда внутренний канал не срабатывает, допустить сигнализацию сразу по внешнему каналу.

28 февраля 2019 г. представительница социал-демократов В. Розьер, выступая в Европарламенте, раскритиковала позицию группы государств-членов - Франции, Германии, Италии, Нидерландов и Австрии, выступавших за ограничение прав информаторов. Евродепутат выразила сожаление, что эти страны поддерживают первоначальное предложение Комиссии о трёхступенчатой процедуре информирования. Наибольшее недовольство Розьер вызвала «лицемерная» позиция её собственной страны - Франции, возглавившей группу ограничителей свободы действий информаторов, которые блокировали переговоры по директиве. Со своей стороны, французский Генеральный секретариат по европейским делам в июле 2018 г. в своём меморандуме со всей определённостью выступил за сохранение последовательности информирования по внешнему и внутреннему каналу ${ }^{2}$. Ссылаясь на свой национальный Закон Сапена-2 о прозрачности, борьбе с коррупцией и модернизации экономики правительство Франции посчитало удаление одного из каналов иерархии информирования противоречащим целям директивы, которая призвана обеспечить баланс отношений между работодателем и наёмным работником.

Пять информаторов из Люксембурга, Германии, Испании, и Италии 27 февраля 2019 г. направили письмо законодателям ЕС, в котором объяснили, что могут посылать сигнал тревоги лишь за пределы организации, где они работают. Если Европарламент согласится с мнением Совета, подчеркнули подписавшие письмо, будущее информаторов в Европе незавидно ${ }^{3}$.

Дэвид Кайе, Специальный докладчик ООН по вопросу о свободе убеждений и их свободному выражению, а также Арлем Дезир, Представитель ОБСЕ по вопросам свободы средств массовой информации в начале марта опубликовали анализ директивы об информаторах, выразив при этом опасения по поводу некоторых её положений ${ }^{4}$. Авторы доклада обратили особое внимание на систему информирования о злоупотреблениях, предложенную Комиссией и поддержанную Советом, прежде всего, на обязательство информаторов задействовать сначала внутренние каналы своей компании, а не обращаться сразу во внешний мир. По мнению правозащитников, данное требование уничтожит всякое стремление информаторов пользоваться каналами сообщений, установленными самими же нанимателями вместо того, чтобы обращаться непосредственно к структурам, отвечающим за соблюдение прав граждан. Использование внутренних каналов организации может, кроме того, перегрузить их сверх возможностей и замедлить рассмотрение сигналов.

Более того, представители ООН и ОБСЕ были серьёзно обеспокоены списком исключений, которые позволяют властям национальных государств запретить поступление сооб-

\footnotetext{
${ }^{1}$ Becker M., Teevs Ch. Warum Bundesregierung und EU-Parlament über Whistleblower straiten/Spiegel online. URL: http://www.spiegel.de/politik/deutschland/whistleblower-wie-die-bundesregierung-sie-schuetzen-will-a-1255344.html.

${ }^{2}$ Bulletin Quotidien Europe, № 12141.

${ }^{3}$ Open letter. European whistleblowers call for a better directive. URL: http://virginieroziere.eu/european-whistleblow ers-call-for-a-better-directive/

${ }^{4}$ Mandate of the Special Rapporteur on the promotion and protection of the right to freedom of opinion and expression. 5 March 2019. URL: https://freedex.org/wp-content/blogs.dir/2015/files/2019/03/OL-OTH-11.2019-1.pdf.
} 
щений информаторов из организаций вовне из соображений национальной безопасности некоторых сведений. По их мнению, положения о полномочиях в сфере ограничения информирования, предоставляемые ведомствам в этом случае, слишком широкие и расплывчатые, поэтому необходимо сузить перечень и определить категории запрещённой информации об обнаруженных нарушениях очень чётко и недвусмысленно.

Согласование директивы вылилось в интенсивные дискуссии между институтами Европейского союза. Главным камнем преткновения ожидаемо стала последовательность процесса уведомления. Парламент выступал за двухступенчатую систему: сначала жалоба должна рассматриваться внутри организации или компетентным ведомством за её пределами, а лишь затем может быть предоставлена журналистам.

Государства-члены же поддержали трёхступенчатый процесс, в соответствии с изначальной законодательной инициативой Комиссии. Такая «лицемерная» позиция возмущала евродепутатов - заставлять осведомителей посылать жалобу внутри компании, как это соотносится с целью защиты их от преследований?

В Совете государства-члены разделились. Франция и Германия жёстко настаивали на обязательном изначальном внутреннем информировании. Великобритания, Ирландия, Португалия, Люксембург, Болгария и Бельгия придерживались позиции, близкой к мнению Европарламента.

Накануне очередного этапа меж-институциональных переговоров 50 организаций, в их числе Transparency International и «Репортёры без границ», призвали институты ЕС принять подход Европарламента. «Возможность разоблачений вне зависимости от отношений работодателя с наёмным работником - это и есть настоящая защита прав информаторов», - написали правозащитники в открытом письме. «Мы серьёзно озабочены намерением институтов ЕС утвердить трёхступенчатый вариант информирования, что усложнит возможности информаторов сообщать о нарушениях законов и злоупотреблениях» ${ }^{1}$.

6 марта 2019 г. после очередных переговоров председательствующая в Совете ЕС Румыния сообщила послам - членам КОРЕПЕР о некоторых сдвигах в меж-институциональных переговорах. Зелёный свет, который дали государства-члены прохождению директивы, стал глотком свежего воздуха в застоявшемся процессе переговоров, которые зашли в тупик по вопросу о последовательности информирования: Совет продолжал настаивать на первоочерёдности внутреннего информирования, тогда как Европарламент выступал за большую гибкость в данном процессе.

Румыния предложила решение вопроса посредством отказа от строго обязательных требований к последовательности информирования, вместо чего информатору будет «настойчиво рекомендовано» использовать всё же сначала внутренние каналы своей организации. Однако если не наблюдается подходящих условий для именно таких действий, информатор может обратиться к компетентным ведомствам вне компании.

Большинство стран ЕС поддержали компромиссное предложение председательства, блокирующее меньшинство в этом случае не возникло. Сторонники строгой последовательности информирования - Франция, Германия, Австрия, Нидерланды и Италия, решили больше не препятствовать утверждению директивы; в своих выступлениях представители Италии и Нидерландов продемонстрировали наибольшую склонность к гибким решениям.

Изменение позиции Германии, а вернее, министра внутренних дел Катарины Барли, принадлежащей к социал-демократам, произошла под воздействием не только со стороны

\footnotetext{
${ }^{1}$ Making whistleblowing work for Europe. URL: https://g8fip1kplyr33r3krz5b97d1-wpengine.netdna-ssl.com/wpcontent/uploads/2019/02/Making_whistleblowing_work_for_Europe.pdf.
} 
СМИ, но и сильным политическим давлением. Жёсткая германская позиция сыграла бы против главного докладчика в Европарламенте по директиве - члена социал-демократической фракции. Председатель фракции в Европарламенте Удо Буллманн приложил немало усилий, чтобы этого не произошло.

Франция, со своей стороны, до последнего момента выступала против любых послаблений в иерархии последовательности информирования, так же, как Австрия и Венгрия, и помышляла об организации очередного блокирующего меньшинства ${ }^{1}$.

Однако планы Франции провалились. Совет министров внутренних дел и юстиции не предоставил Франции такой возможности, а принял компромиссное решение о возможности информаторам обращаться сразу за пределы организации, при этом рекомендовав все же не пренебрегать вначале внутренними каналами.

«Мы считаем, что следует сохранить все три канала, - заявила Вера Юрова, член Комиссии по правосудию и правам граждан, - однако, если информатор имеет разумные сомнения относительно эффективности внутреннего канала, он может обратиться вовне компании сразу по внешнему каналу».

Комиссия полагает, что информатору должна быть предоставлена защита, если он вынесет разоблачительные сведения за пределы своей организации. «Я бы не хотела, чтобы возникла какая-то правовая неопределённость, - подчеркнула Юрова свою приверженность первичному обращению через внутренний канал, так как такая процедура «помогла бы компании провести коррекцию своей деятельности».

Европарламент и Совет вновь встретились 11 марта по требующей решения проблеме последовательности информирования. В результате они договорились о сохранении последовательности, но допустили возможность информаторам обращаться сразу к компетентным властям по внешнему каналу, если нет сомнений в том, что внутренний канал не функционирует. Такое предложение в конечном итоге поддержали все государства-члены, не предоставив Франции шанса организовать блокирующее меньшинство.

Законодатели обсудили в особенности промежуток времени между обращением информаторов по внутреннему и внешнему каналам. Совет настаивал на длительном периоде - 3-6 месяцев, тогда как Парламент предлагал сократить промежуток - 2-4 месяца. Вторым пунктом преткновения стали размеры организации, позволяющие установить внутренний канал информирования: Совет предлагал позволить внутренние каналы для мелких предприятий с персоналом около 50 человек, Парламент же ратовал за расширение возможностей для внешнего информирования, поэтому всегда хотел, чтобы предприятия, где работают менее 250 сотрудников, не имели возможности внутренних каналов.

Ещё одна тема дискуссии - масштабы исключений из директивы в случае, когда информирование наносит ущерб национальной безопасности государства-члена. Совет всегда поддерживал запрет публичных разоблачений, если компетентное ведомство сочтёт переданную информацию угрозой национальной безопасности ${ }^{2}$.

Европейская конфедерация профсоюзов (ETUC) вместе с правозащитными организациями приветствовала политическое согласие по директиве об информаторах, достигнутое 11 марта 2019 г. между Европарламентом и Советом. Профсоюзы объявили об «историческом согласии», «начале изменений в культуре отношений». Наибольший энтузиазм вызвала возможность выбора между сообщениями о злоупотреблении внутри компании или напрямую компетентным властям. Этой уступки Европарламент добился от Совета в трудной и

\footnotetext{
${ }^{1}$ Bulletin Quotidien Europe, № 12208. 07.03.19.

${ }^{2}$ Bulletin Quotidien Europe, № 12211. 12.03.19.
}

Научно-аналитический вестник ИЕ РАН, 2019, №2 
продол-жительной борьбе.

Лишь Европейская федерация журналистов осталась недовольна результатом переговоров, так как надеялась, что информаторам будет разрешено обращаться непосредственно в СМИ, минуя предыдущие стадии разоблачения. В целом же профсоюзы теперь обеспокоены тем, как государства-члены будут переносить положения директивы в национальное законодательство, и будут ли они сами считаться частью внутренних каналов.

18 марта 2019 г. правовой комитет Европарламента единогласно одобрил меж-институциональное соглашение, поддержал его и КОРЕПЕР. В окончательном варианте директива предлагает двухступенчатый вариант информирования: первая ступень - внутренний или внешний канал (сообщение компетентным ведомствам), а затем вторая ступень - обращение в СМИ. В список исключений вошли секретные документы и сведения, которые могут навредить безопасности и обороне государства - такую информацию директива запрещает разглашать.

\section{Выводы}

Согласие по директиве о защите прав информаторов стало кульминацией упорной деятельности Европейской комиссии, начатой ещё в 2017 г., и победой Европарламента, которому в результате длительных и тяжёлых меж-институциональных переговоров удалось склонить Совет к компромиссу относительно последовательности информирования. Компромиссное решение не так просто будет осуществлять на практике: понятно, что информатор пред-почтёт миновать внутренний канал, отправив с большим энтузиазмом жалобу на собственную организацию не её руководству, а внешнему компетентному ведомству. Государствам-чле-нам предстоит создать сеть таких компетентных ведомств - новых бюрократических структур. В то же время законодателям удалось остановить слишком либеральное предложение - разрешить информаторам отправлять жалобы непосредственно журналистам, минуя другие инстанции.

Тем не менее, принятие общеевропейского закона назрело, так как ЕС продолжают сотрясать коррупционные скандалы, поводом которых стало выявление злоупотреблений и нарушений внутри компаний, разоблачённых информаторами.

Пример прохождения директивы интересен, кроме всего прочего, для демонстрации сложного и медленного процесса согласования позиций в законодательном треугольнике ЕС. В данном конкретном случае законодатели были мотивированы приближением выборов в Европарламент, накануне которых нужен был результат успешного решения проблемы. На самом деле, успех начинания буден виден через пару лет, когда государства-члены перенесут положения директивы в свои национальные законодательства.

\section{Список литературы}

Потемкина О.Ю. Кампания по защите прав информаторов. Европейский союз: факты и комментарии, №90, 2017. С. 37-39.

\section{References}

Becker M., Teevs Ch. Warum Bundesregierung und EU-Parlament über Whistleblower straiten/Spiegel online. URL: http://www.spiegel.de/politik/deutschland/whistleblower-wie-diebundesregierung-sie-schuetzen-will-a-1255344.html.

Making whistleblowing work for Europe. URL: https://g8fip1kplyr33r3krz5b97d1-wpengine. 
netdna-ssl.com/wp-content/uploads/2019/02/Making_whistleblowing_work_for_Europe.pdf.

Mandate of the Special Rapporteur on the promotion and protection of the right to freedom of opinion and expression. 5 March 2019. URL: https://freedex.org/wpcontent/blogs.dir/2015/files/2019/03/OL-OTH-11.2019-1.pdf.

Open letter. European whistleblowers call for a better directive. URL: http://virginieroziere.eu/european-whistleblowers-call-for-a-better-directive/

Potemkina O. Campaign to protect the rights of whistleblowers. European Union: facts and comments, №90, 2017. P. 37-39.

Whistleblower Protection in the European Union: analysis of and recommendations on the proposed EU directive. Transparency International. Positionpaper\# 1/ 2018.

Worth M. Safe or Sorry: Whistleblower Protection Laws in Europe Deliver Mixed Results. Blueprint Report Series, 2018. 58 P.

\section{The Rights of Informants in the Center of the Social and Political Life of the EU}

Author. Olga Potemkina, Doctor of Sciences (Politics), Head of the Department of European Integration Studies, Institute of Europe, Russian Academy of Sciences. Address: 11-3, Mokhovaya str., Moscow, Russia, 125009. E-mail: olga_potemkina@mail.ru.

Abstract. The paper evaluates inter-institutional negotiations on the Directive on the protection of whistleblowers' rights. The author shows how the European Parliament succeeded in inducing the Council to compromise in a long and persistent struggle, while the Member States took initially opposite positions on the three-stage informing procedure. The author demonstrates complexity of the legislative process in the European Union, which may take years until legislators give their consent. The positions of MS on the issue of information hierarchy as well as their motivations are shown. The author comes to conclusion that the EU institutions managed to reach agreement on the Directive thanks to forthcoming European Parliament elections, on the eve of which it was important to demonstrate the concrete results of legislative activity.

Key words: whistleblowers, protection of rights, directive, inter-institutional negotiations, trade unions, European Parliament, EU Commission, EU Council, blocking minority.

DOI: http://dx.doi.org/10.15211/vestnikieran220199298

Научно-аналитический вестник ИЕ РАН, 2019, №2 